\title{
Cell-mediated immunity and its glucocorticoid-sensitivity after clinical recovery from severe major depressive disorder
}

\author{
N. Wodarz a, R. Rupprecht ${ }^{\text {a,b }}$, J. Kornhuber ${ }^{\text {a }}$, B. Schmitz ${ }^{\text {a }}$, \\ K. Wild ${ }^{a}$ and P. Riederer ${ }^{a}$ \\ a Department of Psychiatry, Unitersity of Würzburg, Würzlourg and ${ }^{b}$ Max-Planck-Institute for Psychiatry, Munich, FRG \\ (Received 8 July 1991) \\ (Revision received 10 January 1992) \\ (Accepted 21 January 1992)
}

\begin{abstract}
Summary
This follow-up study investigated lymphocyte blastogenesis induced by concanavalin A, phytohemagglutinin $A$, and pokeweed mitcgen and their sensitivity to in vitro dexamethasone administration in 12 patients clinically recovered from severe major depression. Although cortisol-levels at 4.00 p.m. decreased significantly after clinical remission, mitogen-driven lymphocyte proliferative responses were unchanged when assessed intra-individually. No impairment of in vitro glucocorticoid-sensitivity of lectin-induced lymphocyte blastogenesis could be observed in clinically recovered patients. The inhibitory potency of in vitro dexamethasone was found to be inversely correlated with in vivo adrenal cortical hormone levels. There were no correlations with age, weight, sex, antidepressant medication, severity or duration of depression. No differences from age- and sex-matched healthy individuals were found. These results indicate that reduced glucocorticoid receptor sensitivity occurs only during the acute depressive illness.
\end{abstract}

Key words: Major depression; Clinical recovery; Lymphocyte transformation test;

Cell mediated immunity; Glucocorticoid receptor

\section{Introduction}

In recent years, research in the field of affective disorders has paid much attention to alter-

Address for correspondence: N. Wodarz, Department of Psychiatry, University of Würzburg, Füchsleinstr. 15, W-8700 Würzburg, FRG. Fax: 0931/203425. ations in immune system and hypothalamic-pituitary-adrenai axis (HPA) integrity. Approximately $50 \%$ of patients have been shown to have an increased HPA-axis activity during acute depressive illness, e.g., excess cortisol production and resistance to dexamethasone suppression (Carroll et al., 1968; Linkowski et al., 1987). Despite this, they did not display clinical signs of Cushing's syndrome. This might simply be explained by the 
different duration and magnitude of hypercortisolism. On the other hand, an impaired glucocorticoid-mediated negative feedback was detected with a variety of hormones, e.g., ACTH, $\beta$-Endorphin, prolactin, and TSH (Fang et al., 1981; Rupprecht et al., 1987; 1988; 1989). It was reported that these neuroendocrine abnormalities reverse to normal values after clinical recovery of patients with major depression (Linkowski et al., 1987; Rupprecht et al., 1989). As this derangement includes different neuroendocrine systems, this might indicate a more generalized phenomenon of putative pathophysiological significance, at least in a subgroup of patients suffering from major depressive disorder. Moreover, these fundamental neuroendocrine changes should also affect immunocompetent cells.

Glucocorticoids are able to inhibit in vivo and in vitro antigen- and mitogen-induced $T$ lymphocyte proliferation and lymphokine production in a dose-dependent manner. In contrast, only the early activation phase of the B cell cycle is reported to be sensitive to the suppressive effects of glucocorticoids (Cupps and Fauci, 1982; Bowen and Fauci, 1984).

Therefore, peripheral blood mononuclear cells are a suitable tool to study receptor sensitivity and the regulatory potency of glicocorticoids, since these cells possess glucocorticoid receptors and are highly sensitive to glucocorticoids (Cupps and Fauci, 1982).

Recently, we reported a decreased sensitivity of the lymphocyte gluc sorticoid receptor to in vitro added dexamethasone in severely depressed in-patients (Wodarz et al., 1991). This follow-up study in the same cohort of subjects after complete clinical recovery was designed to address the following questions:

(1) Is the integrity of cell-mediated immunity maintained in patients with major depressive disorder (according to DSM-III-R) after complete clinical remission, despite the suspected fundamental changes in neuroendocrine regulation.

(2) Is the impaired glucocorticoid sensitivity of lymphocytes in severely depressed paticnts reversed to normal values after clinical recovery, as

TABLE 1

Demographic and clinical data of the 12 clinically recovered patients with major depressive disorder

\begin{tabular}{|c|c|c|c|c|c|c|}
\hline $\begin{array}{l}\text { age } \\
\text { (y) }\end{array}$ & $\operatorname{sex}$ & DSM-III-R & $\begin{array}{l}\text { HRS-D } \\
\text { depr. }\end{array}$ & $\begin{array}{l}\text { HRS-D } \\
\text { recov. }\end{array}$ & $\begin{array}{l}\text { duration of } \\
\text { treatment } \\
\text { (days) }\end{array}$ & $\begin{array}{l}\text { medication } \\
\text { recov. }\end{array}$ \\
\hline 44 & $F$ & 296.53 & 33 & 10 & 75 & $100 \mathrm{mg}$ ami \\
\hline 66 & $\mathbf{F}$ & 296.33 & 36 & 10 & 28 & $480 \mathrm{mg}$ nor \\
\hline 61 & $\mathrm{~F}$ & 296.34 & 28 & 9 & 24 & $100 \mathrm{mg}$ clo \\
\hline 64 & $F$ & 296.33 & 28 & 1 & 125 & $600 \mathrm{mg}$ lit \\
\hline 39 & $\mathbf{F}$ & 296.33 & 25 & 2 & 30 & $200 \mathrm{mg}$ ami \\
\hline 60 & M & 205.33 & 24 & 1 & 30 & $150 \mathrm{mg}$ ami \\
\hline 60 & $\mathbf{M}$ & 296.33 & 28 & 9 & 90 & $175 \mathrm{mg}$ ami \\
\hline 34 & $F$ & 296.33 & 28 & 10 & 89 & $75 \mathrm{mg}$ clo \\
\hline 54 & $\mathrm{~F}$ & 296.53 & 33 & 1 & 28 & $75 \mathrm{mg}$ ami \\
\hline 18 & $F$ & 296.23 & 26 & 4 & 28 & $175 \mathrm{mg} \mathrm{ami}$ \\
\hline 53 & $\mathbf{M}$ & 296.33 & 26 & 5 & 30 & $20 \mathrm{mg}$ tra \\
\hline 34 & $F$ & 296.33 & 39 & 6 & 95 & $200 \mathrm{mg}$ ani \\
\hline $\begin{array}{r}48.7 \\
+15.1 \\
\end{array}$ & & & $\begin{array}{r}29.5 \\
\pm 4.7\end{array}$ & $\begin{array}{r}5.7 \\
\pm 1.1\end{array}$ & $\begin{array}{c}56 \\
\pm 10.4\end{array}$ & $\begin{array}{l}\text { Mean } \\
\pm \mathrm{SD}\end{array}$ \\
\hline
\end{tabular}

Age (years), sex $(F=$ female; $M=$ male), DSM-IIJ-R (3rd revised version of the diagnostic and statistical manual of the American Psychiatric Association), HRS-D (score on the 21-item Hamilton Rating Scale for Depression; depr.= depressed, recov.= recovered), medication (ami = amitryptiline; nor = nortryptiline; clo = clomipramine; lit = lithium; tra = tranylcypromine). 
it has been reported for other neuroendocrine abnormalities.

(3) Are the results associated with circulating concentrations of adrenal cortical hormones, such as cortisol and ACTH.

(4) Are the results affected by pharmacological treatment, duration of illness or several other variables, such as gender, age, and weight?

\section{Subjects and Methods}

\section{Subjects}

12 subjects (mean age \pm SD: $48.7 \pm 15.1$ years; mean body weight \pm SD: $72.5 \pm 13.4 \mathrm{~kg}$ ), admitted to the psychiatric clinic of the University of Würzburg with severe unipolar major depressive disorder or bipolar depression (according to DSM-III-R) and 13 non-hospitalized healthy controls, closely matched for age, sex and weight (mean age \pm SD: $47.4 \pm 6.4$ years; mean body weight \pm SD: $69.2 \pm 8.6 \mathrm{~kg}$ ) were studied (for demographic and clinical data see Table 1). The severely depressed patients were investigated during the first week after admission to the hospital (Wodarz et al., 1991). They were re-investigated after complete clinical recovery. 4 female depressives and the matched controls were tested during the midluteal phase of the cycle, the other females were postmenopausal.

All subjects were carefully screened for nutritional status and prevalence of medical illness, as well as alcohol or nicotine abuse and stressful life events that might influence pituitary-adrenal or immune system integrity by medical history, physical examination and routine laboratory investigation.

All patients had clinically recovered at the time of this investigation and received pharmacological treatment (Table 1). DSM-III-R (American Psychiatric Association, 1987) diagnoses were made independently by two psychiatrists, who were blind to laboratory investigations. Severity of depression was assessed on the day of laboratory investigations using the 21-item Hamilton Rating Scale for Depression (HRS-D; Hamilton, 1960).

Controls had no history of psychiatric disorder, nor relatives exhibiting psychiatric illness. They were free of any medication and their HRS-D scores were below 5 .

Written informed consent was obtained from all subjects prior to the investigation. This study was approved by the ethical committee of the University of Würzburg.

Assays

All subjects were admitted to a sleep laboratory unit at least one hour prior to blood sampling. For determination of hormonal values and cell-mediated immunity measurements, $50 \mathrm{ml}$ venous blood were collected at 4.00 p.m. into plastic tubes containing EDTA.

\section{Preparation of ceils}

Peripheral blood mononuclear cells (PBMC) were prepared from EDTA-blood under sterile conditions by sodium metrizoate-Ficoll density gradient centrifugation as described previously in detail (Wodarz et al., 1991). Viability of cells always exceeded $95 \%$, as judged from their ability is exclude trypan blue (Pappenheimer, 1917). Contamination by granulocytes and monocytes was always less than $8 \%$.

\section{Cell culture}

Cell cultures were performed exactly as described previously in detail (Wodarz et al., 1991). Briefly, PBMC were suspended at a concentration of $2.5 \times 10^{4} /$ well in culture medium (see details under heading Chemicals) and incubated in triplicate in 96-well microtiter plates (0.2 $\mathrm{ml} /$ well; NUNC, Sweden) for $60 \mathrm{~h}$ to evaluate Con A- and PHA-generated T cell proliferation and for $132 \mathrm{~h}$ to evaluate PWM-generated accessory cell-dependent $\mathrm{B}$ cell proliferation in a sterile, humidified atmosphere $\left(5 \% \mathrm{CO}_{2} / 95 \%\right.$ air $)$. To assess in vitro glucocorticoid sensitivity, $10^{-10}$ to $10^{-6} \mathrm{~mol} / \mathrm{l}$ dexamethasone (DEX) were added to spontaneous (without lectin) and mitogendriven lymphocyte cultures. One optimum and one non-optimum concentration of each lectin was used for mitogen-driven lymphocyte cultures.

To measure DNA-synthesis $0.5 \mu \mathrm{Ci}\left[{ }^{3} \mathrm{H}\right]$ thymidine were added $5 \mathrm{~h}$ prior to termination of the incubation period. Incorporation of $\left[{ }^{3} \mathrm{H}\right]$ thymidine was assessed by rapid filtration through Whatman GF/B filters (Whatman, Maidstone, 
G.B.). The radioisotope was measured by a standard liquid scintillation count in a Beckman LS 5000 TD counter at about $54 \%$ efficiency. All samples were assayed in triplicate. The coefficient of variation was always less than $16 \%$.

\section{Serum hormone determinations}

ACTH was measured by a newly developed immunoradiometric assay (IRMA) supplied by the Nichols Institute (San Juan Capistrano, CA; Raff and Findling, 1989). The lower detection limit was $1.5 \mathrm{pmol} / \mathrm{l}$, and the intra- and interassay coefficients of variation were $3 \%$ and $6.8 \%$, respectively. Cortisol was measured by a direct radioimmunoassay (RIA; Stalla et al., 1981). The lower detection limit was $25 \mathrm{nmol} / \mathrm{l}$, and the intra- and interassay coefficients of variation were $5 \%$ and $9 \%$, respectively.

\section{Chemicals}

$\left[{ }^{3} \mathrm{H}\right]$ Thymidine was obtained from Amersham, G.B. Phosphate buf'ered saline (PBS) was obtained from Boehringer (Mannheim, F.R.G.). Concanavalin A (Con A), phytohemagglutinin A (PHA), pokeweed mitogen (PWM), dexametha- sone and sodium metrizoate-Ficoll were obtained from Sigma (St. Louis, MO), and Rotiszint 22 was obtained from Roth (Karlsruhe, F.R.G.). Con A, PHA, PWM and dexamethasone were diluted to the respective final concent tions with culture medium. The culture medium consisted of Rosewell Park Memorial Institute Medium (RPMI) 1640 (Boehringer, Mannheim, F.R.G.) supplemented with $2 \mathrm{mM}$ L-glutamate (Biochrom, Berlin), $0.1 \mathrm{mg} / \mathrm{ml}$ gentamycine (Biochrom, Berlin, F.R.G.) and $10 \%$ fetal calf serum (FCS, Biochrom, Berlin, F.R.G.). The same lots of lectins and FCS were used throughout the whole investigation to limit methodological variations.

\section{Statistical analysis}

Lymphocyte proliferation was expressed in terms of a stimulation index (SI) defined by the ratio stimulated (in the presence of lectin) counts per minute (CPM) divided by spontaneous (in the absence of lectin) CPM. The results are mean \pm SD, except where otherwise stated. Hormone values below the detection limit of our assays were recorded as the respective detection limits. Data

TABLE 2

Hormone values and lymphocyte proliferative responses of patients with major depressive disorder and controls

\begin{tabular}{|c|c|c|c|}
\hline & $\begin{array}{l}\text { Controls } \\
N=13\end{array}$ & $\begin{array}{l}\text { Patients } \\
\text { depr. } \\
N=12\end{array}$ & $\begin{array}{l}\text { Patients } \\
\text { recov. } \\
N=12\end{array}$ \\
\hline Cortisol: & $225.7 \pm 77.3$ & $273.1 \pm 104.8$ & $194.3 \pm 77.9 \mathrm{nmol} / 1$ \\
\hline ACTH: & $3.6 \pm 0.8$ & $4.2 \pm 1.5$ & $4.6 \pm 1.9 \mathrm{pmol} / 1$ \\
\hline & stimulation : & & \\
\hline \multicolumn{4}{|l|}{ optimum } \\
\hline $10.0 \mu \mathrm{g} / \mathrm{ml}$ PHA: & $28.0 \pm 5.0$ & $23.4 \pm$ & $18.9 \pm 4.2$ \\
\hline $10.0 \mu \mathrm{g} / \mathrm{ml} \operatorname{Con} \mathrm{A}:$ & $15.1 \pm 2.4$ & $14.7 \pm$ & $17.9 \pm 3.1$ \\
\hline $10.0 \mu \mathrm{g} / \mathrm{ml} \mathrm{PWM:}$ & $17.5 \pm 3.1$ & $21.9 \pm 4.2$ & $17.1 \pm 6.3$ \\
\hline \multicolumn{4}{|l|}{ non-optimum } \\
\hline $1.0 \mu \mathrm{g} / \mathrm{m} 1 \mathrm{PHA}:$ & $9.2 \pm 1.4$ & $9.4 \pm$ & $8.9 \pm 1.7$ \\
\hline $1.0 \mu \mathrm{g} / \mathrm{ml}$ Con A: & $5.6 \pm 0.9$ & $4.0 \pm$ & $4.8 \pm 0.6$ \\
\hline $1.0 \mu \mathrm{g} / \mathrm{ml}$ PWM: & $11.7 \pm 2.4$ & $15.9 \pm$ & $11.9 \pm 4.6$ \\
\hline
\end{tabular}

The mean $\pm S D$ hormone values are expressed in pmol/1 and the mean $\pm S^{\top}$. lymphocyte proliferative responses by terms of a stimulation index [defined by the ratio stimulated (in the presence of lectin) counts per minute (CPM) vs. spontaneous (in the absence of lectin) CPM]; phytohemagglutinin A (PHA); Concanavalin A (Con A); pokeweed mitogen (PWM). Cortisol-values at 4.00 p.m. decreased significantly intra-individually in patients with major depression after clinical recovery $(P<0.05)$. The results obtained during the acutely depressed state vs. control subjects were discussed in detail in a previous report (Wodarz et al., 1991). 
were analyzed using Pearson's product-moment correlation, $t$-test for dependent variables, and analysis of covariance (ANCOVA). All significance levels are two-tailed.

\section{Results}

\section{Cell viability}

Under culture conditions of the lymphocyte proliferation assay, the mean cell viabilities at the time of harvest (day 3 and day 5) were $96.8 \% \pm$ $1.4 \%$ and $94.9 \% \pm 2.5 \%$, respectively.

\section{Descriptive statistics}

Table 1 summarizes important demographic and clinical data of the 12 patients studied after clinical recovery. There were no significant differences in age, weight and hormone values between the control and patient group. Patients with major depressive disorder exhibited significantly decreased cortisol-values at 4.00 p.m. after clinical recovery $(t=2.31 ; P<0.05)$, whereas ACTH-values did not change significantly.

No significant correlations could be seen between age, weight, HRS-D score, duration of treatment, medication and hormone values. Corisol- and ACTH-values were significantly correlated in recovered patients $(\mathrm{r}=-0.65, P=0.024$, $N=12$ ), but not in the same patients suffering from acute depressive illness $(\mathrm{r}=0.38, P=0.24$, $N=12$ ).

\section{Lectin-induced lymphocyte blastogenesis}

Table 2 shows the hormone values and the lymphocyte proliferative responses after stimulation with one optimum and one non-optimum concentration of each lectin. Blastogenesis did not differ significantly between healthy individuals and patients, irrespective of the lectin and the concentration used.

No significant correlations could be observed between lymphocyte responses to PWM, Con A or PHA and age, weight, HRS-D score or cortisol-values. Only PHA-induced lymphocyte blastogenesis was significantly associated with cortisolvalues at $4.00 \mathrm{pm}$. in recovered patients (Table 3). No significant influence of treatment with tricyclic antidepressants could be detected.

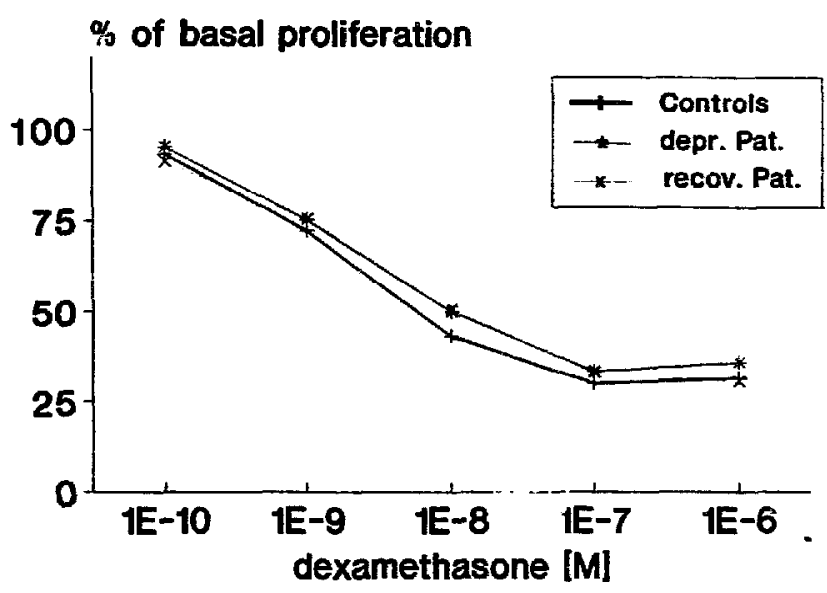

Fig. 1. Effect of $10^{-10}-10^{-6} \mathrm{M}$ in vitro dexamethasone on 1.0 $\mu \mathrm{g} / \mathrm{ml}$ PHA-induced lymphocyte blastogenesis (arithmetic means, not adjusted for in vivo cortisol; standard deviations (SD) were omitted for reasons of clarity). Fven after covarying out serum cortisollevels, the differences between healthy controls $(N=13)$ and recovered patients $(N=12)$ were not statistically significant. The issilts obtainec during the acutely depressed statz ys. sontroi suyects were discussed in detail in a previous report I Wodarz et al., 1991).

Sensitivity of iymphocyte proliferation to in vitro added dexamethasone

In vitro administration of DEX produced a dose-dependent decrease of spontaneous, PHA(Fig. 1) and Con A-induced T-lymphocyte proliferative responses (Fig. 2) in healthy controls and patients. No suppressive effects of DEX could be

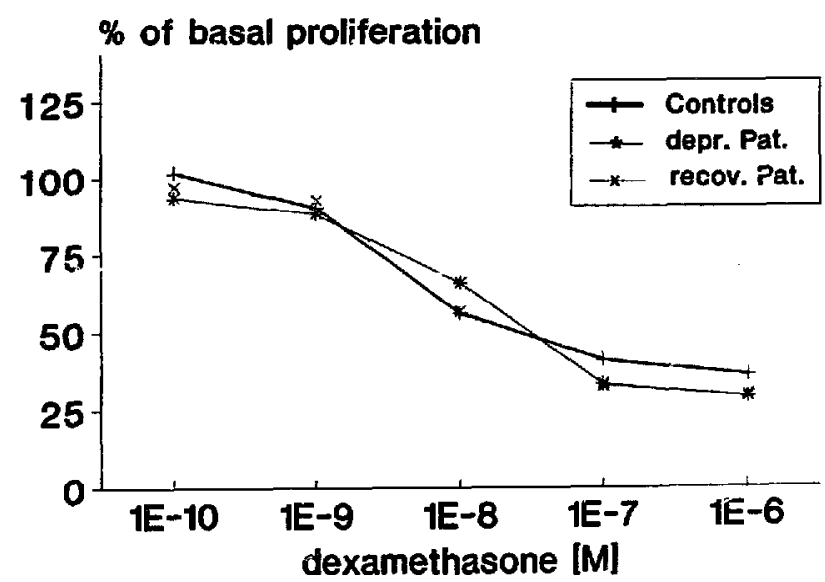

Fig. 2. Effect of $10^{-10}-10^{-6} \mathrm{M}$ in vitro dexamethasone on 1.0 $\mu \mathrm{g} / \mathrm{ml}$ Con A-induced lymphocyte blastogenesis (arithmetic means, not adjusted for in vivo cortisol; SD were omitted for reasons of clarity). The differences between healthy controls $(N=13)$ and recovered patients $(N=12)$ were not statistically significant. The results obtained during the acutely depressed state vs. control subjects were discussed in detail in a previous report (Wodarz et al., 1991). 


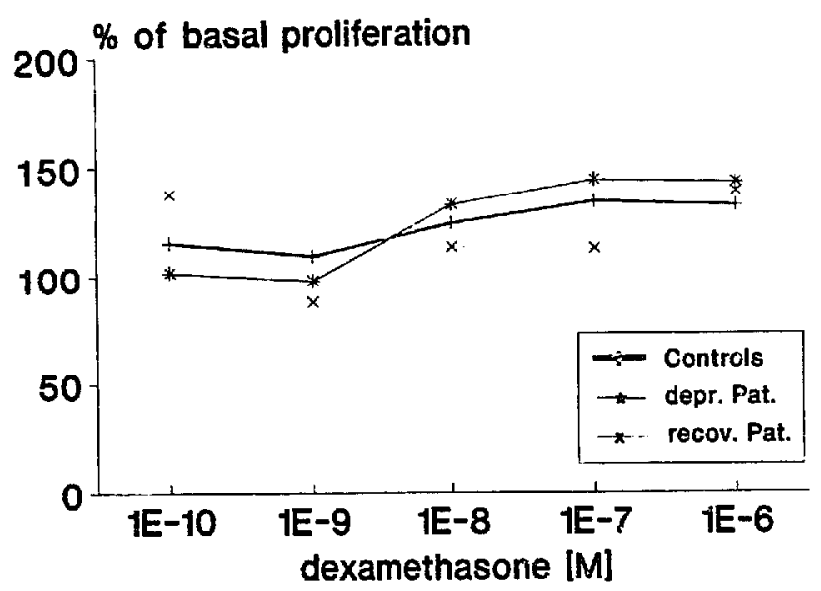

Fig. 3. Effect of $10^{-10}-10^{-6} \mathrm{M}$ in vitro dexamethasone on $10.0 \mu \mathrm{g} / \mathrm{ml}$ PWM-induced lymphocyte blastogenesis (arithmetic means, not adjusted for in vivo cortisol; SD were omitted for reasons of clarity). The differences between healthy controls $(N=13)$ and recovered patients $(N=12)$ were not statistically significant. The results obtained during the acutely depressed state vs. control subjects were discussed in detail in a previous report (Wodarz et al., 1991).

observed on PWM-driven aczessory cell-dependent B-cell blastogenesis in all individuals (Fig. 3). The inhibitory potency of in vitro DEX on PHA-induced T-cell proliferation was significantly associated with serum cortisol-levels at 4.00 p.m. in recovered patients (Table 3 ).

No significant correlations could be observed between in vivo levels of adrenal cortical hormones and the DEX-induced inhibition of cells

\section{TABLE 3}

Correlations between in vivo cortisol-levels and in vitro sensitivity of phastimulated lymphocyte blastogenesis to dexamethasone in recovered patients with major depressive disorder

\begin{tabular}{lll}
\hline $\begin{array}{l}\text { DEX } \\
{[\mathrm{mol} / \mathrm{l}]}\end{array}$ & $1.0 \mu \mathrm{g} / \mathrm{ml}$ & $10.0 \mu \mathrm{g} / \mathrm{ml} \mathrm{PHA}$ \\
\hline without & Cortisol & Cortisol \\
$10^{-10}$ & $-0.77^{*}$ & $-0.64^{\circ}$ \\
$10^{-9}$ & $-0.79^{*}$ & $-0.84^{* *}$ \\
$10^{-8}$ & $-0.75^{*}$ & $-0.82^{* *}$ \\
$10^{-7}$ & $-0.75^{*}$ & $-0.81^{* *}$ \\
$10^{-6}$ & $-0.64^{\circ}$ & $-0.84^{* *}$ \\
\hline
\end{tabular}

$N=12$; dexamethasone [mol/1]; correlation coefficient $r$; ${ }^{*} * P<0.005$; ${ }^{*} P<0.05 ;{ }^{\circ} P<0.1$; stimulated with optimum or non-optimum concentrations of Con A and PWM. Since a significant association of in vivo hormone levels and in vitro PHA-driven T-blastogenesis could be established (Table 3), it seemed useful to examine this statistically. An analysis of covariance adjusted the individuals' in vitro lymphocyte proliferation for the respective in vivo hormone values, i.e., covaried out the inf'uence of in vivo hormone levels. Nevertheless, there were no significant differences in DEX-sensitivity of spontaneous, PWM-, PHA- and Con A-stimulated lymphocytes between healthy individuals and recovered patierts with major depressive disorder.

\section{Discussion}

We recently reported that PHA-stimulated Tlymphocytes of severely depressed in-patients exhibited a significantly decreased sensitivity to in vitro dexamethasone (Wodarz et al., 1991). This follow-up in the same cohort of subjects demonstrates that the impaired lymphocyte glucocorticoid sensitivity is reversed to normal values after clinical recovery of patients with major depressive disorder. Other abnormalities in neuroendocrine regulation were also reported to be state dependent, e.g., 24-hour hypersecretion of cortisol and the disturbed response to dexamethasone (Linkowski et al., 1987; Rupprecht et al., 1989).

Our severely depressed patients tended to have higher cortisol-levels than healthy individuals (Wodarz et al., 1991). There was a significant decrease of cortisol-levels at $4.00 \mathrm{pm}$. intra-individually after clinical recovery. Nevertheless, the association between in vitro glucocorticoid sensitivity of PHA-driven T-blastogenesis and in vivo cortisol levels at 4.00 p.m. persisted in recovered patients. Moreover, the missing correlation of ACTH and cortisol during the depressed state could be observed again after clinical recovery.

Since lymphocyte glucocorticoid receptor density was found to be unchanged in depressed patients (Schlechte and Sherman, 1985; Rupprecht et al., 1991), our results might further support the hypothesis of a glucocorticoid receptor dysfunction in patients with major depressive disorder. 
Lowy et al. (1988) have also described a weaker DEX-induced suppression of lymphocyte blastogenesis, but only after stimulation with Con $\mathrm{A}$. This discrepancy might be mainly attributed to methodological differences (e.g., time of blood sampling and concentrations of lectins), as well as differences in selection criteria of patients (e.g., dexamethasone suppressors and non-suppressors). But it has to be noticed that both observations point in the same direction. However, Lowy et al. (1988) did not perform a follow-up in their patients after clinical recovery.

Studies on the integrity of cell-mediated immunity in patients with major depressive disorder have been inconsistent. Some groups reported normal in vitro lymphocyte responses to the lectins Con A, PHA and PWM (Albrecht et al., 1985; Lowy et al., 1988; Darko et al., 1989; Schleifer et al., 1989), whereas others found a significantly decreased (Kronfol et al., 1986; Calabrese et al., 1987; Cosyns et al., 1989; Levy et al., 1991) or even increased response (Altshuler et al., 1989) to some lectins in depressed patients compared to various control groups.

All these groups did not re-investigate patients after clinical improvement. Therefore, this follow-up study re-investigated a cohort of subjects with major depressive disorder, who exhibited no significant disturbance in the lymphocyte transformation test during severe depressive illness (Wodarz et al., 1991). We could not demonstrate any significant differences in lectin-induced $T$ and B-lymphocyte blastogenesis between the severely depressed and clinically recovered state. Moreover, there were no differences to this measure of cell-mediated immunity in age- and sex-matched healthy individuals.

The above cited studies differed quite considerably in the methodology applied (e.g., concentrations of lectins, incubation period), as well as selection criteria of patients (e.g., diagnostic criteria, severity of depression, medication, age, sex), as discussed previously in detail (Wodarz et al., 1991).

We were not able to establish an association between lectin-induced lymphocyte blastogenesis and factors like age, gender or weight in our clinically recovered patients. This is in accordance with previous work (Albrecht et al., 1985;
Kronfol et al., 1986; Cosyns et al., 1989) and our own results (Wodarz et al., 1991) during the depressive syndrome.

Moreover, we could not observe a correlation between in vitro lymphocyte blastogenesis and in vivo levels of adrenal cortical hormones in our recovered patients. This is in accordance with results in other laboratories (Darko et al., 1989; Kronfol and House, 1989; Schleifer et al., 1989) and our own findings during the depressed state (Wodarz et al., 1991).

There were no significant effects of antidepressant medication, duration of treatment or number of depressive episodes on lectin-induced lymphocyte proliferative responses.

Despite the variety of fundamental changes in neuroendocrine regulation during the acute depressed state and after complete clinical recovery, the integrity of cell-mediated immunity could obviously be maintained in patients with major depressive disorder. But the impaired in vitro glucocorticoid sensitivity of PHA-induced T-cell blastogenesis during acute depressive illness may indicate that this fragile homeostasis might be difficult to maintain, if additional disturbances occur (e.g., pharmacological induced, as well as physiological, shifts in hormonal balance).

Further analysis of glucocorticoid receptor functionality (e.g., by means of in vivo and in vitro chal!enge studies) should be performed to define the pathophysiological relevance of the state-dependent impaired receptor sensitivity in patients with major depressive disorder.

\section{References}

Albrecht, J., Helderman, J.H., Schlesser, M.A. and Rush, A.J. (1985) A controlled study of cellular immune function in affective disorders before and during somatic therapy. Psychiatry Res. 15, 185-193.

Altshuler, L.L., Plaeger Marshall, S., Richeimer, S., Daniels, M. and Baxter, L.R., Jr. (1989) Lymphocyte function in major depression. Acta Psychiatr. Scand. 80, 132-136.

American Psychiatric Association and Committee on Nomenclature and Statistics (1987) Diagnostic and Statistical Manual of Mental Disorders revised 3rd edition, Washington: American Psychiatric Association.

Bowen, D.L. and Fauci, A.S. (1984) Selective suppressive effects of glucocorticoids on the early events in the human $B$ cell activation process. J. Immunol. 133, 1885-1890.

Calabrese, J.R., Kling, A.C. and Targum, S.D. (1987) Alter- 
ations in immunocompetence during stress, bereavement, and depression: focuses on neuroendocrine regulation. Am. J. Psychiatr. 144, 1123-1134.

Carroll, B.J., Martin, F.I. and Davis, B.M. (1968) Resistance to suppression by dexamethasone of plasma 11-OHCS levels in severe depressive illness. Br. Med. J. 3, 285-287.

Cosyns, P., Maes, M., Vandewoude, M., Stevens, W.J., De Clerck, L.S. and Schotte, C. (1989) Impaired mitogen-induced lymphocyte responses and the hypothalamic-pituitary-adrenal axis in depressive disorders. J. Affect. Disord. $16,41-48$.

Cupps, T.R. and Fauci, A.S. (1982) Corticosteroid-mediated immunoregulation in man. Immunol. Rev. 65, 133-155.

Darko, D.F., Gillin, J.C., Risch, S.C., Bulloch, K., Golshan, S., Tasevska, Z. and Hamburger, R.N. (1989) Mitogen-stimulated lymphocyte proliferation and pituitary hormones in major depression. Biol. Psychiatry 26, 145-155.

Fang, V.S., Tricou, B.J., Robertson, A. and Meltzer, H.Y. (1981) Plasma ACTH and cortisol levels in depressed patients: relation to the dexamethasone suppression test. Life. Sci. 29, 931-938.

Hamilton, M. (1960) A rating scale for depression. J. Neurol. Neurosurg. Psychiatry 23, 56-62.

Kitayama, I., Janson, A.M., Cintra, A., Fuxe, K., Agnati, L.F., Ögren, S.O., Härfstrand, A., Eneroth, P. and Gustafsson, J.A. (1988) Effects of chronic imipramine treatment on glucocorticoid receptor immunoreactivity in various regions of the rat brain. J. Neural. Transm. 73, 191-203.

Kronfol, Z., House, J.D., Silva, J., Jr., Greden, J. and Carroll, B.J. (1986) Depression, urinary free cortisol excretion and lymphocyte function. Br.J. Psychiatry 148, 70-73.

Kronfol, Z. and House, J.D. (1989) Lymphocyte mitogenesis, immunuglobulin and complement levels in depressed patients and normal controls. Acta Psychiatr. Scand. 80, 142-147.

Levy, E.M., Borrelli, D.J., Mirin, S.M., Salt, P., Knapp, P.H., Peirce, C., Fox, B.H. and Black, P.H. (1991) Biological measures and cellular immunological function in depressed psychiatric inpatients. Psychiatr. Res. 36, 157-167.

Linkowski, P., Mendlewicz, J., Kerkhofs, M., Leclercq, R., Golstein, J., Brasseur, M., Copinschi, G. and van Cauter, E. (1987) 24-hour profiles of adrenocorticotropin, cortisol, and growth hormone in major depressive illness: effect of antidepressant treatment. J. Clin. Endocrinol. Metab. 65, 141-152.

Lowy, M.T., Reder, A.T., Gormley, G.J. and Meltzer, H.Y. (1988) Comparison of in vivo and in vitro glucocorticoid sensitivity in depression: relationship to the dexamethasone suppression test. Biol. Psychiatry 24, 619-630.
Pappenheimer, A.M. (1917) Exper:mental studies upon lymphocytes: I. The reactions of lymphocytes under various experimental conditions. J. Exp. Med. 25, 633-636.

Pepin, M.C., Beaulieu, S. and Barden, N. (1989) Antidepressants regulate glucocorticoid receptor messenger RNA concentrations in primary neuronal cell cultures. Mol. Brain Res. 6, 77-83.

Raff, H. and Findling, J.W. (1989) A new immunoradiometric assay for corticotropin evaluated in normal subjects and in patients with Cushing's disease. Clin. Chem. 35, 596-600.

Rupprecht, R., Barocka, A., Jecht, E., Noder, M., Pichl, J. and Schwarz, M. (1987) Prolactin response to dexamethasone: a study on normal controls and depressed patients. Acta Psychiatr. Scand. 76, 139-143.

Rupprecht, R., Barocka, A., Beck, G., Schrell, U. and Pichl, J. (1988) Pre- and postdexamethasone plasma ACTH and $\beta$-endorphin levels in endogenous and non-endogenous depression. Biol. Psychiatr. 23, 531-535.

Rupprecht, R., Rupprecht, C., Rupprecht, M., Noder, M. and Mahlstedt, J. (1989) Triiodothyronine, thyroxine and TSH response to dexamethasone in depressed patients and normal controls. Biol. Psychiatry 25, 22-32.

Rupprecht, R., Kornhuber, J., Wodarz, N., Göbel, C., Lugauer, J., Sinzger, C., Müller, O.A. and Riederer, P. (1990) Characterization of glucocorticoid receptor binding capacity in human mononuclear leukocytes: increase by metyrapone is prevented by dexamethasone pretreatment. J. Neuroendocrinol. 2, 803-806.

Rupprecht, R., Kornhuber, J., Wodarz, N., Lugauer, J., Göbel, C., Riederer, P. and Beckmann, H. (1991) Lymphocyte glucocorticoid receptor binding during depression and after clinical recovery. J. Affect. Disord. 22, 31-35.

Schlechte, J.A. and Sherman, B. (1985) Lymphocyte glucocorticoid receptor binding in depressed patients with hypercortisolemia. Psychoneuroendocrinology 10, 469-474.

Schleifer, S.J., Keller, S.E., Bond, R.N., Cohen, J. and Stein, M. (1989) Major depressive disorder and immunity. Role of age, sex, severity, and hospitalization. Arch. Gen. Psychiatr. 46, 81-87.

Stalla, G.K., Giesemann, G., Müller, O.A., Wood, W.G. and Scriba, P.C. (1981) The development of a direct homologous radioimmunoassay for serum cortisol. J. Clin. Chem. Clin. Biochem. 19, 427-434.

Wodarz, N., Rupprecht, R., Kornhuber, J., Schmitz, B., Wild, K., Braner, H.U. and Riederer, P. (1991) Normal lymphocyte responsiveness to lectins but impaired sensitivity to in vitro glucocorticoids in major depression. J. Affect. Disord. $22,241-248$. 